\title{
Maintenance of the Undifferentiated State in Myogenic Progenitor Cells by TGF $\beta$ Signaling is Smad Independent and Requires MEK Activation
}

\author{
Tetsuaki Miyake ${ }^{1}$, Arif Aziz ${ }^{1}$ and John C. McDermott 1,2,3,4,*(D) \\ 1 Department of Biology, York University, 4700 Keele Street, Toronto, ON M3J 1P3, Canada; \\ tmiyake@yorku.ca (T.M.); Arif.Aziz@mnp.ca (A.A.) \\ 2 Muscle Health Research Centre (MHRC), York University, Toronto, ON M3J 1P3, Canada \\ 3 Centre for Research in Biomolecular Interactions (CRBI), York University, Toronto, ON M3J 1P3, Canada \\ 4 Centre for Research in Mass Spectrometry (CRMS), York University, Toronto, ON M3J 1P3, Canada \\ * Correspondence: jmcderm@yorku.ca; Fax: +(416)-736-5698
}

Received: 3 December 2019; Accepted: 4 February 2020; Published: 5 February 2020

\begin{abstract}
Transforming growth factor $\beta$ (TGF $\beta$ ) is a pluripotent cytokine and regulates a myriad of biological processes. It has been established that TGF $\beta$ potently inhibits skeletal muscle differentiation; however, the molecular mechanism is not clearly defined. Previously, we reported that inhibition of the TGF $\beta$ canonical pathway by an inhibitory Smad, Smad7, does not reverse this effect on differentiation, suggesting that activation of receptor Smads (R-Smads) by TGF $\beta$ is not responsible for repression of myogenesis. In addition, pharmacological blockade of Smad3 activation by TGF $\beta$ did not reverse TGF $\beta$ 's inhibitory effect on myogenesis. In considering other pathways, we observed that TGF $\beta$ potently activates MEK/ERK, and a pharmacological inhibitor of MEK reversed TGF $\beta$ 's inhibitory effect on myogenesis, as indicated by a myogenin promoter-reporter gene, sarcomeric myosin heavy chain accumulation, and phenotypic myotube formation. Furthermore, we found that c-Jun, a known potent repressor of myogenesis, which is coincidently also a down-stream target of MEK/ERK signaling, was phosphorylated and accumulates in the nucleus in response to TGF $\beta$ activation. Taken together, these observations support a model in which TGF $\beta$ activates a MEK/ERK/c-Jun pathway to repress skeletal myogenesis, maintaining the pluripotent undifferentiated state in myogenic progenitors.
\end{abstract}

Keywords: TGF $\beta$; MEK; muscle; differentiation

\section{Introduction}

TGF $\beta$ is the prototype of a large family of pluripotent cytokines with diverse effects on cellular proliferation, tumor growth, apoptosis, differentiation, fibrosis, anti-inflammation, and embryo development [1-5]. The competence of TGF $\beta$ cytokine signaling plays an important role in determining lineage acquisition in cells of mesenchymal origin, most notably by determining osteogenic or myogenic commitment [6]. The potency of TGF $\beta$ signaling at physiological levels in myogenic cells has been known for some time although dissection of the molecular pathway(s) mediating its cellular effects is still fragmentary.

The general canonical view that has been established for TGF $\beta$ signaling is that it binds to its cognate type II receptor, which facilitates receptor complex formation and activation of the cytoplasmic serine/threonine kinase activity of the type I receptor leading to phosphorylation of Smad2/3 (receptor regulated Smads: R-Smads). Phosphorylation of R-Smads at the C-terminal SXS motif results in association with the common Smad, Smad4, and translocation into the nucleus to regulate target gene transcription through complex interactions with heterogeneous transcription complexes $[7,8]$. While 
this pathway is pervasive in mediating TGF $\beta$ effects, a number of non-canonical aspects of TGF $\beta$ signaling have also been reported $[9,10]$.

Previously, we observed that an inhibitory Smad (I-Smad), Smad7, potently counteracts Smad3 activation by TGF $\beta$ in a myogenic cell line. However, exogenous Smad7 was unexpectedly not able to prevent inhibition of muscle differentiation by TGF $\beta$ [11]. These observations indicate that TGF $\beta$ inhibits muscle differentiation through a Smad independent pathway. In further support for this idea, myostatin, a member of the TGF $\beta$ family and a regulator of skeletal muscle differentiation, also activates Smad2/3 by phosphorylation of the SXS motif of the R-Smads in a manner analogous to TGF $\beta$. However, exogenous expression of Smad7 reverses the inhibitory effect of myostatin but not that of TGF $\beta$ [11]. Thus, several lines of evidence suggest that repression of myogenesis by TGF $\beta$ is mediated by a pathway distinct from the canonical R-Smad pathway. Here, we found that TGF $\beta$ activates MEK/ERK signaling. MEK activation subsequently represses the transcriptional activity of MyoD [12-14]. Importantly, a MEK-specific inhibitor, U0126 [15], reverses the inhibitory effect of TGF $\beta$ on myogenic differentiation, whereas pharmacological blockade of Smad3 signaling was without effect. These findings indicate that MEK, and not Smad3, activation is the primary mechanism underlying TGF $\beta$ 's inhibitory action on myogenesis. These observations reveal the involvement of a TGF $\beta$-MEK pathway in maintaining myogenic precursor cells in the undifferentiated state and also place TGF $\beta$ at a strategic nexus to control the differentiation of pluripotent mesenchymal cells into different lineages.

\section{Results}

2.1. Inhibition of TGF $\beta$ Mediated Smad3 Phosphorylation Does not Reverse the Inhibitory Effect of TGF $\beta$ on Muscle Differentiation

We previously found that although exogenous Smad7 strongly repressed Smad3 activation by TGF $\beta$, the inhibition of muscle differentiation by TGF $\beta$ was not rescued by exogenous expression of Smad7 [11]. These observations suggested that TGF $\beta$ inhibits muscle differentiation in a R-Smad independent manner. To test this possibility, we inhibited Smad3 activation using a chemical inhibitor, SIS3 [16,17]. In agreement with previous observations, SIS3 strongly repressed TGF $\beta$ induced phosphorylation of Smad3 (Figure 1A). In the absence of SIS3, TGF $\beta$ potently enhanced the activity of 3TP-Lux and (CAGA)X13-Luc reporter genes, which are Smad3 dependent and TGF $\beta$ responsive reporter genes, respectively $[18,19]$. The activation of these two reporter genes by TGF $\beta$ was strongly repressed by SIS3 indicating the efficacy of SIS3 inhibition of Smad3 activation (Figure 1B). However, at the same concentration at which SIS3 strongly inhibits phosphorylation and activation of Smad3, SIS3 failed to reverse TGF $\beta$ 's inhibitory effect on muscle differentiation as assessed by myotube formation and myosin heavy chain (MyHC) accumulation (Figure 1C). In congruence with previous results, both SIS3 and Smad7 greatly reduced TGF $\beta$ induced Smad3 activity, but neither reversed TGF $\beta$ 's inhibitory effect on muscle differentiation (Figure 1C) [11]. Taken together, these observations strongly suggest that activation of Smad3 by TGF $\beta$ is insufficient for myogenic repression. 

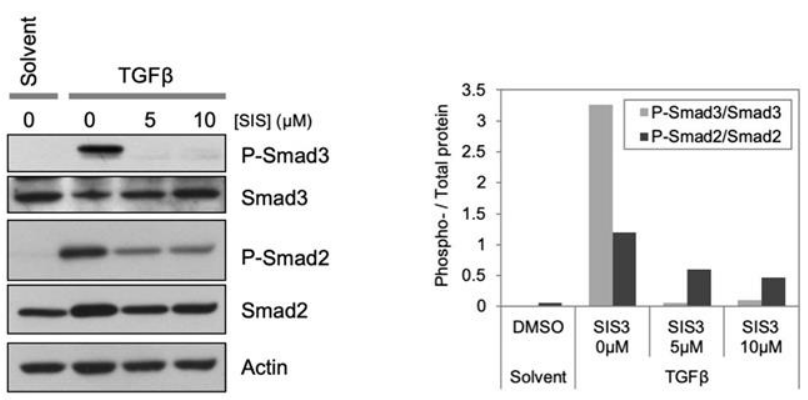

(A)
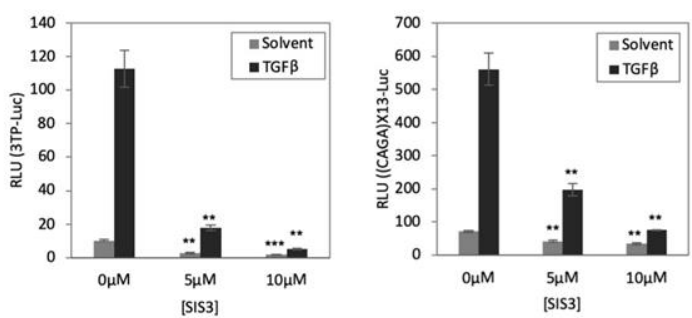

(B)
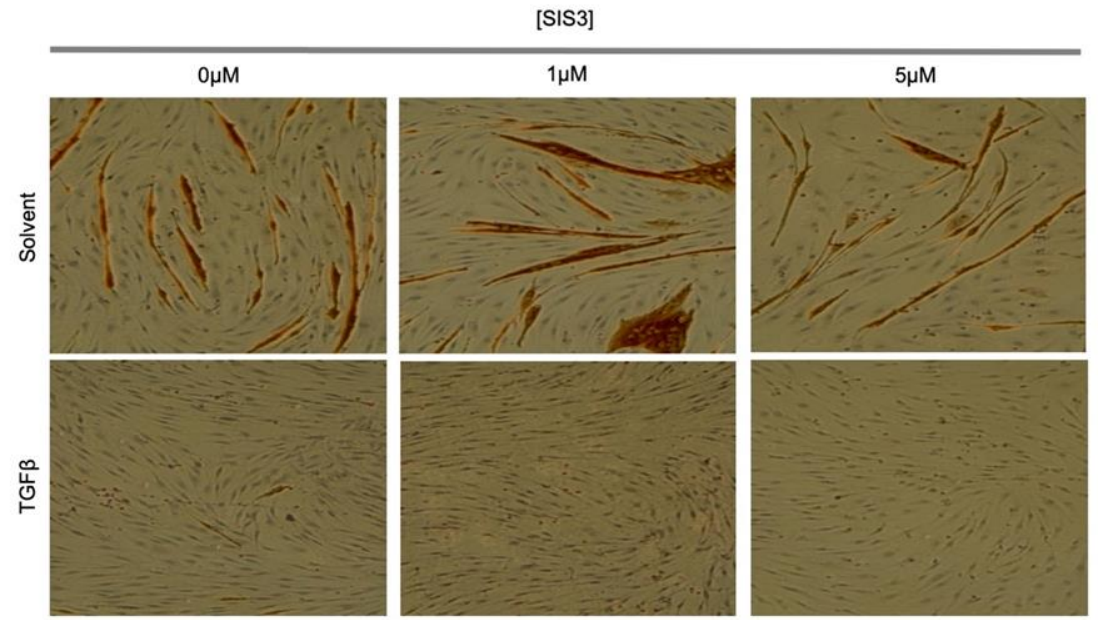

(C)

Figure 1. Inhibition of transforming growth factor $\beta$ (TGF $\beta$ ) mediated Smad3 phosphorylation does not reverse the inhibitory effect of TGF $\beta$ on muscle differentiation. (A) C2C12 cells were seeded onto cell culture plates at equal density and maintained in TGF $\beta(1 \mathrm{ng} / \mathrm{mL})$ with or without indicated concentrations of SIS3. Total protein samples were extracted from the cells and equal amounts of total protein $(20 \mu \mathrm{g})$ were subjected to Western blotting analysis. The levels of indicated proteins were assessed by a standard immuno-blotting technique with a specific primary antibody. Actin indicates equal amounts of protein loading into each lane (left panel). Quantification of the band intensity of the P-Smad2 and P-Smad3, and total Smad2 and Smad3 in the left panel were measured by ImageJ, and the ratios of the band intensity of the phospho- to the corresponding total-protein band were graphed (right panel). (B) C2C12 cells were transfected with either 3TP-lux (left panel) or (CAGA)X13-luciferase reporter gene construct (right panel), and to monitor transfection efficiency, pCMV- $\beta$-gal construct was included in each condition. The transfected cells were maintained for $16 \mathrm{~h}$ in TGF $\beta(1 \mathrm{ng} / \mathrm{mL})$ with or without indicated concentrations of SIS3. Total protein samples were harvested with a luciferase lysis buffer. Luciferase activity (RLU: relative luciferase unit) in each condition was measured independently and normalized according to $\beta$-galactosidase activity. $(n=3,+/-\mathrm{SD})$. The $p$-value was calculated relative to the control by two tailed T-Test $\left.{ }^{* *} p<1 \times 10^{-3}{ }^{* * *} p<1 \times 10^{-5}\right)$. (C) C2C12 cells were seeded onto cell culture plates at equal density and maintained in TGF $\beta(1 \mathrm{ng} / \mathrm{mL})$ with or without indicated concentrations of SIS3 for $48 \mathrm{~h}$. The cells were fixed and stained for muscle myosin heavy chain (MyHC) detection by immunochemistry. The photomicrographs are representative fields in each condition. 


\subsection{TGF $\beta$ Stimulates MEK Phosphorylation}

We hypothesized that if Smad3 activation is insufficient to inhibit muscle differentiation, TGF $\beta$ must activate a non-canonical pathway to repress myogenesis. We did note that TGF $\beta$-treated $\mathrm{C} 2 \mathrm{C} 12$ cells reached a high density and survived better in differentiation medium (DM) (unpublished observation). This observation warrants further investigation into the possible effects of TGF $\beta$ on myoblast proliferation and survival. In other cell models, TGF $\beta$ has been observed to activate the MEK/ERK pathway $[20,21]$, and we therefore assessed the MEK/ERK pathway as a potential target for TGF $\beta$ signaling in muscle cells. Previously, we documented that MEK activation is required for maintaining the undifferentiated state of myoblasts since a member of the IL-6 family, cardiotrophin-1 (CT-1), inhibits myogenesis through MEK activation [22]. Therefore, we treated C2C12 cells with recombinant TGF $\beta$ as well as CT- 1 as a positive control to assess phosphorylation levels of MEK and Stat3.

Assessment of the MEK signaling pathway activation by immuno-blotting with antibodies recognizing the total and phosphorylated forms of MEK revealed that phosphorylated MEK was enhanced in $\mathrm{C} 2 \mathrm{C} 12$ cells treated with TGF $\beta(2 \mathrm{ng} / \mathrm{mL})$ compared to that in solvent treated control cells. TGF $\beta$ was more potent than CT- $1(10 \mathrm{ng} / \mathrm{mL})$ in terms of MEK activation based on the ratio of P-MEK to total MEK (Figure 2). Since we previously observed that CT-1 $(10 \mathrm{ng} / \mathrm{mL})$ potently inhibits muscle differentiation in a MEK activation dependent manner [22], and the amount of phosphorylated MEK due to TGF $\beta$ treatment was higher than that of CT-1, we reasoned that TGF $\beta$-mediated MEK activation in $\mathrm{C} 2 \mathrm{C} 12$ cells may be sufficient to inhibit muscle differentiation. These results led us to postulate that TGF $\beta$ primarily inhibits myogenesis by activation of the MEK signaling pathway.
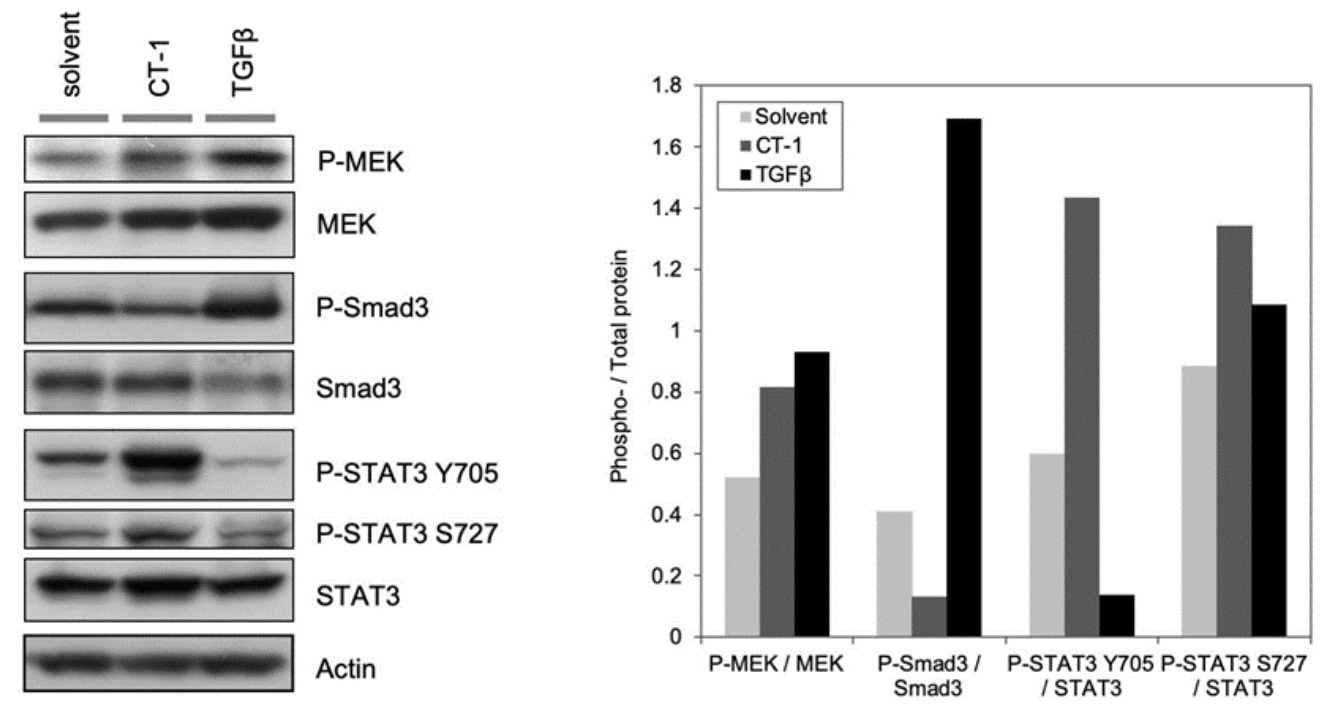

Figure 2. TGF $\beta$ stimulates MEK phosphorylation. C2C12 cells were seeded onto cell culture plates at equal density and maintained in TGF $\beta(1 \mathrm{ng} / \mathrm{mL})$, CT-1 $(10 \mathrm{ng} / \mathrm{mL})$, or solvent. Total protein samples were extracted from the cells and equal amounts of total protein $(20 \mu \mathrm{g})$ were subjected to Western blotting analysis. The levels of indicated proteins were assessed by a standard immuno-blotting technique with a specific primary antibody. Actin indicates equal amounts of protein loading into each lane (left panel). The experiment was done three times. Quantification of band intensity of the phospho- and corresponding total protein in the left panel were measured using ImageJ, and the ratios of the band intensity of the phospho- to the corresponding total protein band were graphed in each condition (right panel). 
2.3. Inhibition of MEK Activation by a Pharmacological Inhibitor Partially Reverses the Inhibitory Effect of TGF $\beta$ on Muscle Differentiation

We next tested the possibility that prevention of MEK activation by a MEK-specific inhibitor might activate myotube formation and MyHC accumulation in the presence of TGF $\beta$ activation. As seen in Figure 3A, C2C12 cells cultured in DM for $72 \mathrm{~h}$ without exogenous TGF $\beta$ formed large multinucleated myotubes, and these myotubes accumulated a molecular differentiation marker (MyHC-brown stain). In the presence of exogenously added TGF $\beta$ in DM, as previously observed by us and several other groups [23-25], most of the cells maintained their mono-nucleated undifferentiated phenotype, and accumulation of MyHC was not observed (Figure 3B). This undifferentiated phenotype with exogenous TGF $\beta$ administration was essentially reversed by treatment of the cells with the MEK inhibitor, U0126, in a dose-dependent manner (Figure 3A). These data indicate that MEK is a key down-stream target of TGF $\beta$ signaling, and the activation of MEK contributes considerably to the inhibition of muscle differentiation.
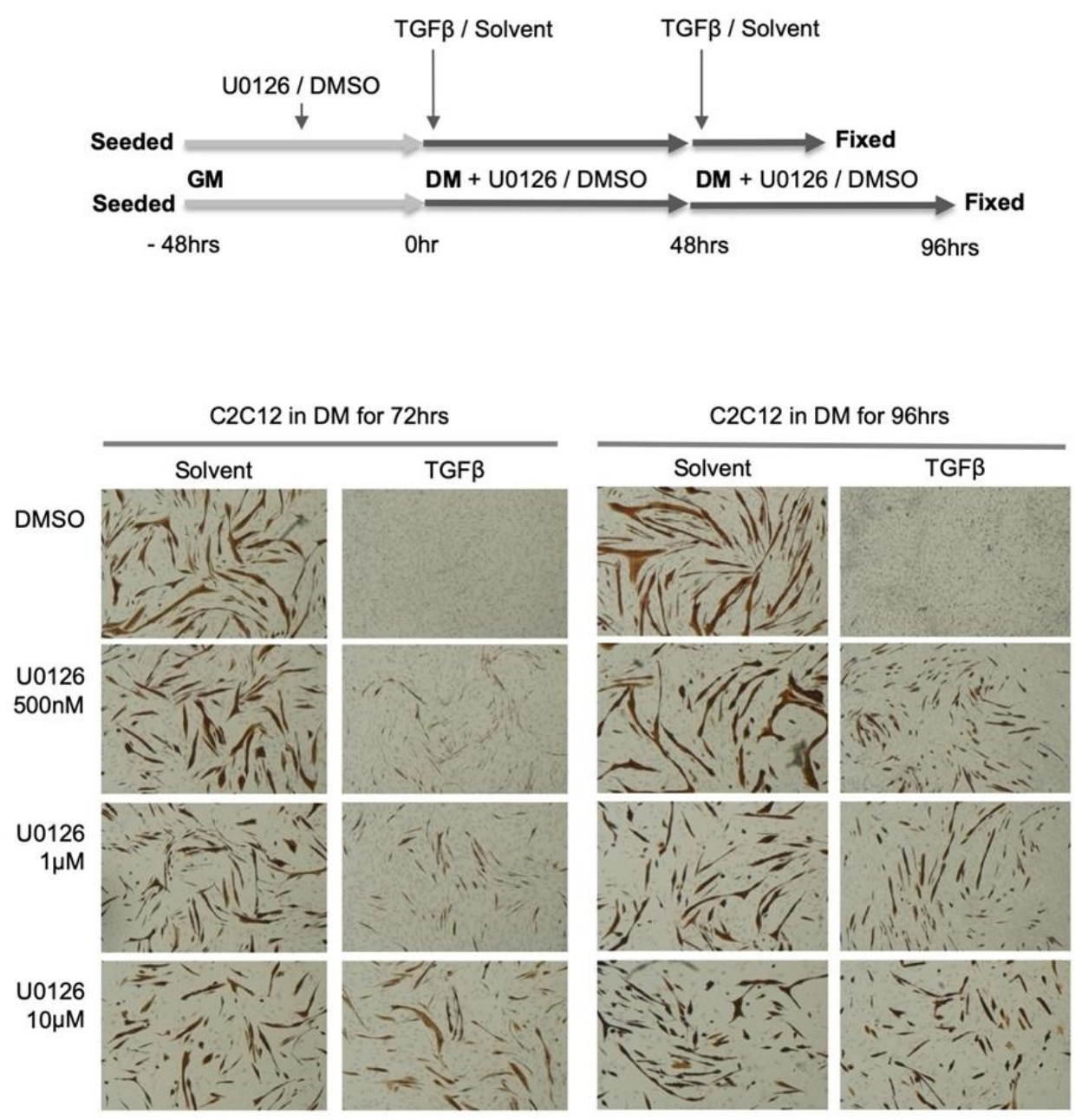

(A)

Figure 3. Cont. 

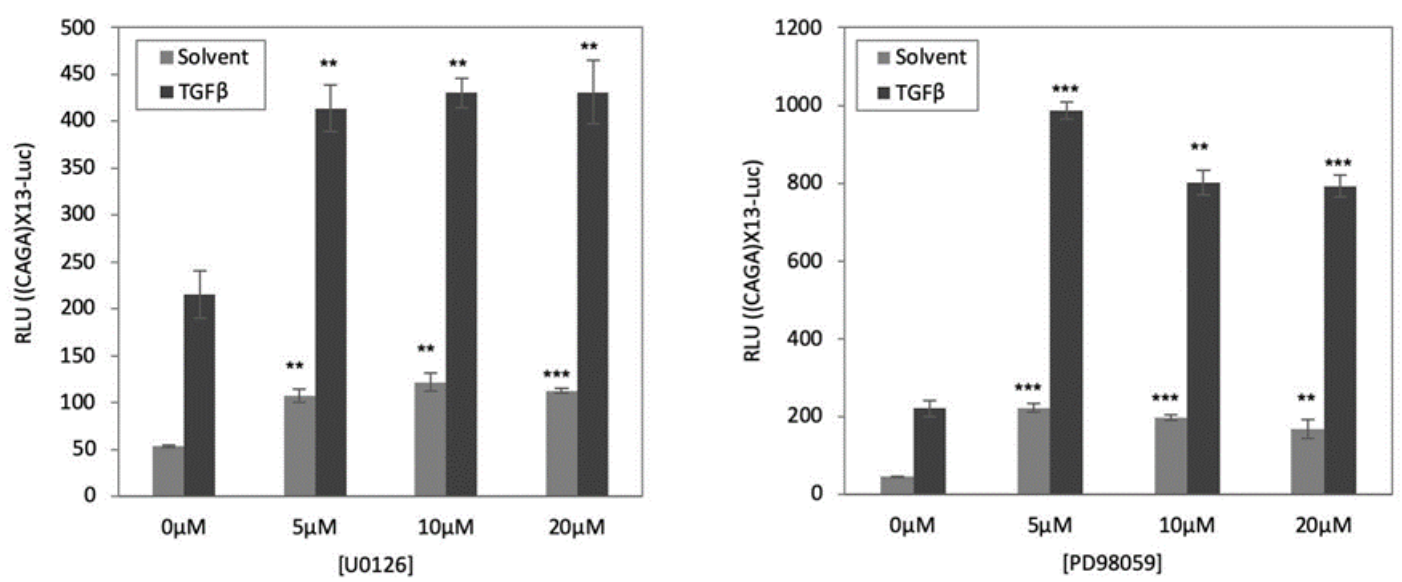

(B)

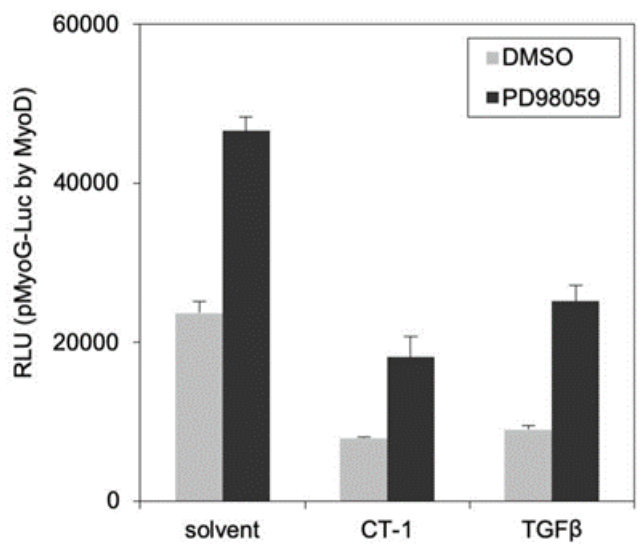

(C)

Figure 3. Pharmacological inhibition of MEK activation partially reverses the inhibitory effect of TGF $\beta$ on muscle differentiation. (A) $\mathrm{C} 2 \mathrm{C} 12$ cells were seeded onto cell culture plates at equal density and maintained in TGF $\beta(1 \mathrm{ng} / \mathrm{mL})$ or solvent with or without indicated concentrations of U0126 for 72 (left panel) and $96 \mathrm{~h}$ (right panel). The cells were fixed and stained for muscle myosin heavy chain (MyHC) detection by immunochemistry (upper panel). The photomicrographs are representative fields in each condition (lower panel). (B) C2C12 cells were transfected with (CAGA)X13-luciferase reporter gene construct, and to monitor transfection efficiency, pCMV- $\beta$-gal construct was included in each condition. The transfected cells were maintained for $16 \mathrm{~h}$ in TGF $\beta(1 \mathrm{ng} / \mathrm{mL})$ or solvent with or without indicated concentrations of U0126 (left panel) or PD98059 (right panel). Total protein samples were harvested with a luciferase lysis buffer. Luciferase activity (RLU: relative luciferase unit) in each condition was measured independently and normalized according to $\beta$-galactosidase activity $(n=3,+/-\mathrm{SD})$. The p-value was calculated relative to the control by two tailed T-Test (** $\left.p<1 \mathrm{X} 10-3{ }^{* * *} p<1 \mathrm{X} 10-5\right)$. (C) C2C12 cells were transfected with myogenin promoter-luciferase reporter gene construct (pMyoG-Luc) with MyoD expression vector, and to monitor transfection efficiency, pCMV- $\beta$-gal construct was included in each condition. The transfected cells were maintained for $16 \mathrm{~h}$ in TGF $\beta(1 \mathrm{ng} / \mathrm{mL}), \mathrm{CT}-1$ (10ng/mL), or solvent with or without indicated concentrations of PD98059. Total protein samples were harvested with a luciferase lysis buffer. Luciferase activity in each condition was measured independently and normalized according to $\beta$-galactosidase activity. $(n=3,+/-\mathrm{SD})$.

Reversal of TGF $\beta$ mediated myogenic repression by MEK inhibition is not due to inhibition of Smad signaling since MEK/ERK signaling positively modulates R-Smad activity by phosphorylating the linker region of Smad2/3 [26-29]. In our experiments, MEK inhibition caused an increase in the 
activity of a TGF $\beta$ reporter gene consistent with the idea that MEK/ERK inhibition de-represses the R-Smads [27,29] (Figure 3B). Thus, MEK inhibition does not rescue myogenesis by repressing TGF $\beta$ induced R-Smad activation. These data further support the idea that R-Smad activation is absolutely unnecessary for myogenic repression by TGF $\beta$.

\subsection{MEK-Specific Inhibitors Reverse the Repression of the Myogenin Promoter by TGF $\beta$}

If MEK phosphorylation and subsequent nuclear accumulation are required for inhibition of muscle differentiation by TGF $\beta$, we next tested whether MEK-specific pharmacological inhibitors might reverse TGF $\beta$ mediated repression of myogenic transcriptional activation properties [13] as quantified by the transcriptional activation of the myog gene, which is a critical myogenic target gene in the hierarchical control of myogenesis [30-32]. To assess this, a myog promoter-luciferase reporter gene (pMyoG-luc) was utilized. C2C12 cells were transfected with this reporter gene construct and a MyoD expression vector to fully activate the promoter. The transfected cells were treated with a MEK-specific inhibitor, PD98059, or DMSO (diluent), and TGF $\beta$ protein or its solvent. CT-1 treatment was included as a positive control in this analysis. TGF $\beta$ as well as CT- 1 reduced MyoD driven myog promoter activation (Figure 3A). In the presence of PD98059 $(10 \mu \mathrm{M})$, neither TGF $\beta$ nor CT-1 was able to inhibit myog transcriptional activity efficiently suggesting the requirement for MEK signaling for myogenic repression by CT- 1 and TGF $\beta$ (Figure 3C). Although we activated this promoter with exogenous MyoD expression, it is important to acknowledge that other myogenic regulators assembled on the myog promoter are also likely affected by MEK signaling (as discussed below). Therefore, these data indicate that TGF $\beta$ mediated MEK activation is required for the inhibition of a primary myogenic target gene, the myog gene.

\subsection{TGF $\beta$ Signaling Modulates Myogenic Co-Activator and Co-Repressor Proteins}

Previously, we reported that Smad7 can physically and functionally co-operate with MyoD in promoting myogenesis [11]. In this study, we found that Smad7 protein level is reduced by TGF $\beta$ treatment (Figure 4A). Since MyoD can bind to and activate the Smad7 promoter [11], this effect is likely mediated by interference with MyoD transcriptional properties and repression of this positive feed-forward loop by TGF $\beta$. Secondly, we also found here that TGF $\beta$ signaling enhances the nuclear levels of phospho-MEK/-ERKs (Figure 4A, left panel) and phospho-c-Jun (Figure 4A, left and right panels), a well-established target of activated MEK signaling and a well characterized co-repressor of MyoD function $[12,14]$. Our data analyzing the myog promoter confirms this myogenic repression and also indicates that exogenous Smad7 expression cannot over-ride this repression (Figure 4A,B), which is consistent with Smad7's inability to inhibit TGF $\beta$ mediated myogenic repression [11]. Therefore, the primary inhibition of the myog promoter results from downregulation of $\mathrm{MyoD}$ and myogenic co-activators such as Smad7, and induction of co-repressors such as c-Jun. We suggest that these molecular events constitute a mutually reinforcing network to lock the cells in an undifferentiated state. 

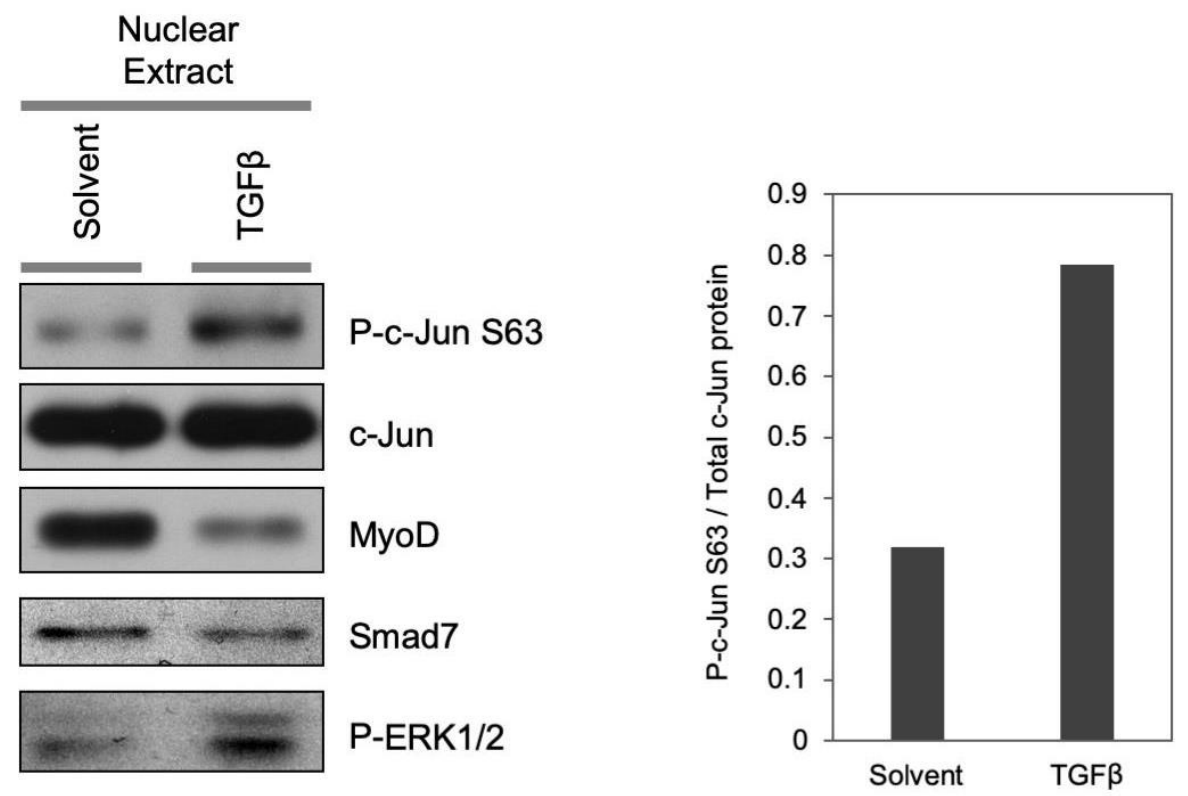

(A)

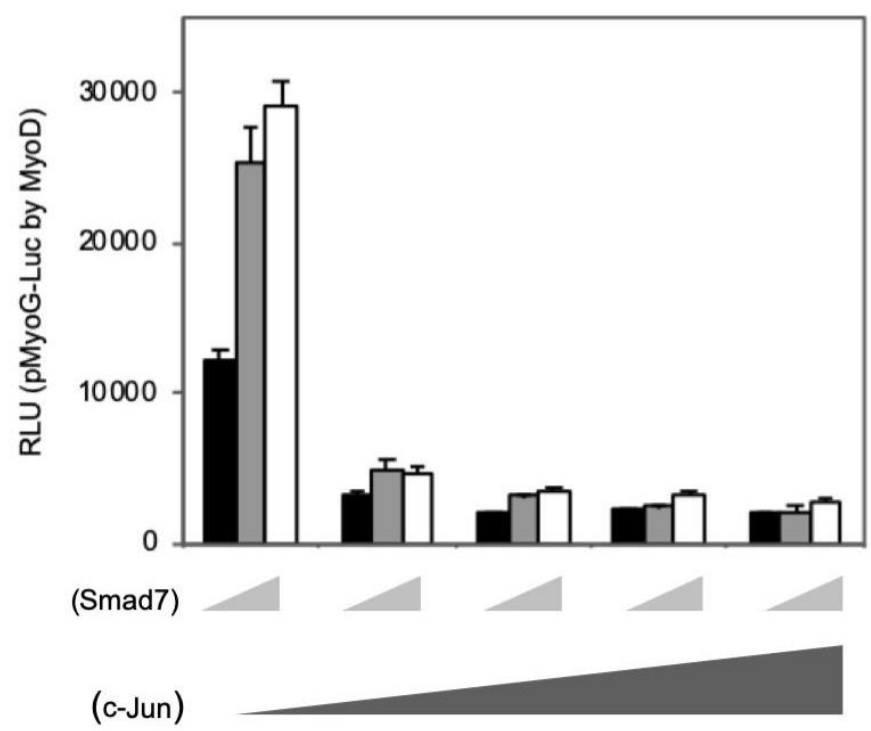

(B)

Figure 4. TGF $\beta$ signaling modulates MyoD co-activator and co-repressor proteins. (A) C2C12 cells were seeded onto cell culture plates at equal density and maintained in TGF $\beta(1 \mathrm{ng} / \mathrm{mL})$ or solvent in DM for $16 \mathrm{~h}$. Nuclear protein was extracted by using NE-PER ${ }^{\circledR}$. The amount of indicated nuclear protein was visualized with standard Western blotting technique (left panel). The band intensity of P-c-Jun and total c-Jun were measured using ImageJ, and the ratio of the P-c-Jun to the c-Jun band intensity was graphed in the presence and absence of TGF $\beta$ (right panel). (B) C2C12 cells were transfected with myogenin promoter-luciferase reporter gene construct (pMyoG-Luc) with MyoD expression vector, and increasing amounts of c-Jun expression vector $(0,0.1,0.4,0.8,1.6 \mu \mathrm{g})$ and combinations with Smad7 expression vector $(0,0.5$, and $1 \mu \mathrm{g})$. In addition, to monitor transfection efficiency, pCMV- $\beta$-gal construct was included in each condition. The transfected cells were maintained for $16 \mathrm{~h}$ in DM. Total protein samples were harvested with a luciferase lysis buffer. Luciferase activity in each condition was measured independently and normalized according to $\beta$-Galactosidase activity $(n=3,+/-\mathrm{SD})$. 


\section{Discussion}

It is widely assumed that TGF $\beta$ inhibits skeletal muscle differentiation through activation of the canonical TGF $\beta / S \operatorname{mad} 3$ pathway. However, we have made several key observations disputing this idea. First, Smad7, an inhibitory Smad, reversed the inhibitory effect of myostatin but not TGF $\beta$ on myogenesis even though Smad7 potently inhibits Smad3 activation induced by both myostatin and TGF $\beta$ [11]. Second, although a Smad3 specific inhibitor, SIS3, potently inhibited TGF $\beta$-induced Smad3 phosphorylation and subsequent activation of TGF $\beta / S \operatorname{Smad} 3$ dependent gene expression, it did not reverse the inhibitory effect of TGF $\beta$ on myogenesis. Third, a MEK inhibitor reverses TGF $\beta$ 's inhibitory effect on myogenesis, which suggests a non-canonical pathway for myogenic repression. Fourth, nuclear Smad7, which is incapable of inhibiting the TGF $\beta / S m a d 3$ "canonical" pathway, is sufficient to enhance myogenesis [33]. These observations clearly indicate that TGF $\beta$ inhibits muscle differentiation independent of activation of R-Smads.

\subsection{Is MEK Activation a Common Effector of TGF $\beta$ Family Cytokines?}

TGF $\beta$ is known to activate the MEK/ERK pathway [20,34], and we recently found that this MAPK pathway plays an important role in maintenance of the undifferentiated state of myogenic precursor cells by CT-1 [22], and now in the current study, by TGF $\beta$. Interestingly, it has been documented that BMP4, which is a known inhibitor of myogenic cell specification during embryo development [35] and a member of the TGF $\beta$ superfamily, induces neuronal differentiation in a Ras/ERK dependent manner [36]. In the current study, we found that MyoD levels are decreased due to TGF $\beta$ treatment, which likely contributes to the repression of myogenesis. In addition, the increase observed in the active form of c-Jun is also relevant since this has previously been shown to post-translationally inhibit MyoD function [12,14]. The reduction in Smad7 levels are also relevant in view of reports implicating Smad7 in regulation of $\mathrm{C} 2 \mathrm{C} 12$ terminal differentiation $[11,33]$. Moreover, we have also recently documented that Smad7/MyoD are components of a large myogenic protein complex assembled on the regulatory region of some myogenic genes [37]. Therefore, multiple changes in these myogenic regulators are mediated by TGF $\beta$-MEK/ERK activation.

Thus, these observations suggest the possibility that TGF $\beta$ cytokines commonly invoke MEK activation to restrict or promote lineage acquisition depending on the cellular context. Further analysis of this idea is therefore warranted in the search for molecular regulators of cellular programming and re-programming.

A detailed analysis of Smad-independent TGF $\beta$ target genes may be enlightening in documenting these non-canonical effects of TGF $\beta$ signaling. Consistent with our observations, it was reported that $c-j u n, j u n b$, and smad7 genes are regulated by TGF $\beta$ in a Smad4-independent manner [38]. These observations suggest that regulation of $c-j u n$, junb, and smad7 gene expression by TGF $\beta$ would not be affected by inhibition of R-Smad activity, although this idea remains to be tested. Furthermore, exogenous Smad7 expression could not reverse TGF $\beta^{\prime}$ s inhibitory effect on insulin-like growth factor binging protein-5 (IGFBP5) synthesis in C2C12 myoblasts (MBs) [39].

\subsection{TGF $\beta$ Signaling in Muscle Pathologies}

It has been reported that TGF $\beta$ signaling is increased in a number of muscle pathologies $[40,41]$. For example, canonical TGF $\beta$ signaling acutely increases when dystrophic muscle is stimulated to contract leading to fibrosis and muscle dysfunction in both mice and flies [40]. TGF $\beta 1$ levels increase rapidly in skeletal muscle after injury [42]. The post-natal muscle dysfunction observed in a number of studies has been largely attributed to the excessive fibrosis that occurs due to hyperactivated TGF $\beta$ signaling [43]. No doubt this is a major contributor to the pathology, however, it is tempting to speculate that an additional consideration, based on our data, is that the muscle progenitor cells (satellite cells) in diseased or injured muscle are inhibited from differentiating by TGF $\beta$ signaling, which might also contribute to muscle atrophy, inefficient repair and dysfunction. One study also 
indicated that a TGF $\beta$-dependent conversion of muscle progenitors to a pro-fibrotic myofibroblast phenotype may also occur [43]. Chronic failure to differentiate progenitor cells in disease contexts could result in a progressive loss of contractile muscle mass-a fundamental hallmark of cachexia, which has also been linked with excessive TGF $\beta$ signaling [41].

The identification of MEK as a potent effecter of TGF $\beta$ signaling in myogenic cells will allow this pathway to be manipulated pharmacologically in a variety of contexts. Inhibiting this pathway with neutralizing antibodies or small molecule inhibitors could prove efficacious in muscle pathologies. Also, programming of multipotent mesenchymal cells or induced pluripotent stem cells may benefit from the characterization of signaling pathways that can efficiently repress or promote specific differentiation pathways in order to allow systematic programming and/or manipulation of cell identity and differentiation status.

In summary, we have characterized the mechanism of TGF $\beta$ 's inhibitory effect on myogenic cell differentiation at the molecular level. TGF $\beta$-mediated repression of myogenesis is primarily dependent on MEK activation. Unexpectedly, TGF $\beta$ effects on myogenesis are unequivocally independent of R-Smad activation. Molecular dissection of TGF $\beta$ effects on myogenesis will allow further insights into its role during development and post-natal physiology and pathology of skeletal muscle.

\section{Materials and Methods}

\subsection{Plasmids}

Smad7 and Smad7T expression vectors were described previously [11]. An activated $(\Delta \mathrm{N} 3$ S218D/S222E) human MEK1 expression construct was a gift from A. Natalie [44]. p3TP-Lux reporter construct was from J. Wrana (University of Toronto; Program in Molecular Biology and Cancer, Samuel Lunenfeld Research Institute, Mount Sinai Hospital; Toronto, Canada). (CAGA)X13-Luc reporter construct was generated by insertion of 13X (CAGA) sequence from the pai-I promoter [19] followed by a $c$-fos minimal promoter in the pGL3-basic (Promega; USA) luciferase reporter vector. pCMV- $\beta$-galactosidase have been described elsewhere [11]. The myogenin promoter region was excised from pMyoG-luc by SacI/Bgl II digestion. The resultant 1152bp fragment was inserted at the SacI/Bgl II sites of pGL4-10 vector (Promega, USA). The dsRed2-N1 expression vector was purchased from Clontech Laboratories; USA. All constructs used in this study were verified by DNA-sequencing (York University Molecular Core Facility; Toronto, Canada).

\subsection{Antibodies}

The primary antibodies used in this study were obtained from Santa Cruz Biotechnology; USA; MyoD (C-20), Actin(I-19) from Cell Signaling Technology; MEK1/2 (9122), phospho-MEK1/2 (Ser217/221) (9121), STAT3 (9132), phospho-STAT3 Y705 (9135), S727 (9136), Smad3 (9513), phospho-Smad3 (9514), Smad2 (3122), and phospho-Smad2 (3101) from DakoCytomation; USA; MyoD1 (clone:5.8A; M3512).

\subsection{Cell Culture}

C2C12 myoblast were obtained from the American Type Culture Collection; USA and cultured in growth medium (GM) consisting of $10 \%$ fetal bovine serum (FBS) (HyClone; Canada) in high-glucose Dulbecco's modified Eagle's medium (DMEM) (Gibco, USA) supplemented with 1\% penicillin-streptomycin (Gibco; USA) at $37^{\circ} \mathrm{C}$ and $5 \% \mathrm{CO}_{2}$. Myotube formation was induced by replacing GM with differentiation medium $(D M)$, which consisted of $2 \%$ horse serum (Atlanta Biologicals; USA) in DMEM supplemented with $1 \%$ penicillin-streptomycin. For TGF $\beta$ or CT-1 treatment, recombinant human TGF $\beta$ (R\&D system; USA; 240-B) or CT-1 (R\&D system; 438-CT) was resuspended with solvent $(4 \mathrm{mM} \mathrm{HCl}, 0.1 \%$ bovine serum albumin (BSA)) and added into the media. For myotube formation assays, DM with TGF $\beta(1 \mathrm{ng} / \mathrm{mL})$ or CT-1 $(10 \mathrm{ng} / \mathrm{mL})$ was replenished every 2 days. Inhibitors (PD98059 (9900), U0126 (Cell Signaling Technology, Canada; 9903), and SIS3 ((2E)-1-(6,7-Dimethoxy-3,4-dihydro-1H-isoquinolin-2-yl)-3-(1-methyl-2-phenyl-1H-pyrrolo[2-b]pyridin- 
3-yl)-propenone hydrochloride (Sigma-Aldric;, Canada, S0447) were resuspended with DMSO and added into the cell culture media for $30 \mathrm{~min}$ prior to adding TGF $\beta$.

\subsection{Microscopy}

Phase contrast photomicrographs were obtained using an epifluorescence microscope (Axiovert 35; Carl Zeiss MicroImaging; Canada), with appropriate phase and filter settings, and either 4X NA 0.10 or 10X NA 0.25 Achrostigmat objective lenses. Images were recorded with a digital camera (Canon, EOS D6; Japan).

\subsection{Nuclear Protein Extraction}

Nuclear proteins were extracted from the cells by NE-PER ${ }^{\circledR}$ kit (Pierce) according to the manufacturer's protocol.

\subsection{Western Blotting Analysis}

Total cellular protein extracts were prepared in NP-40 lysis buffer $(0.1 \% \mathrm{NP}-40,150 \mathrm{mM} \mathrm{NaCl}$, $1 \mathrm{mM}$ EDTA, $50 \mathrm{mM}$ Tris-HCl pH 8.0, $1 \mathrm{mM}$ sodium vanadate, $1 \mathrm{mM}$ PMSF, supplemented with a protease inhibitor cocktail (Sigma; Canada, P-8340)). Protein concentrations were determined by a standard Bradford assay (BioRad; USA). Equivalent amounts of protein were resolved by SDS-PAGE gels, followed by electrophoretic transfer to an Immobilon-P membrane (Millipore; Canada) as directed by the manufacturer (Millipore). Blots were incubated with the indicated primary antibody in $5 \%$ milk in PBS or Tris buffered saline (TBS)-T (10mM Tris-HCl pH8.0, $150 \mathrm{mM} \mathrm{NaCl}, 0.1 \%$ Tween-20) or 5\% Bovine serum albumin (BSA) in TBS-T according to the manufacturer's protocol at $4^{\circ} \mathrm{C}$ overnight with gentle agitation. After washing briefly, the blots were incubated with the appropriate HRP-conjugated secondary antibodies in 5\% milk in PBS or TBS-T at room temperature according to the manufacturer's protocols (Santa Cruz Biotechnology, USA, Cell Signaling Technology, USA). After being washed three times with 1XPBS or 1XTBS (depending on the primary antibody) at room temperature, the blots were treated with the enhanced chemiluminescence reagent (Amersham; USA) to detect immuno-reactive proteins. The immunoblots were exposed to Biomax film (Koda;, USA) for visual representation. The band intensity was measured using ImageJ and graphed.

\subsection{Immunochemistry}

C2C12 cells were washed with phosphate buffered saline (PBS) (pH7.4) and fixed with 90\% methanol at $-20^{\circ} \mathrm{C}$ for $10 \mathrm{~min}$. After fixation, the cells were incubated in $5 \%$ milk in PBS for $30 \mathrm{~min}$ at $37^{\circ} \mathrm{C}$ for blocking. Cells were incubated at room temperature with MF-20 (primary antibody) diluted in blocking buffer ( $5 \%$ milk PBS) for $1 \mathrm{~h}$. After incubation, the cells were washed three times with PBS and incubated for $60 \mathrm{~min}$ at room temperature with a horseradish peroxidase (HRP)-conjugated $\alpha$-mouse secondary antibody. The cells were washed again three times with PBS and incubated in developer $\left(0.6 \mathrm{mg} / \mathrm{mL}\right.$ DAB, $0.1 \% \mathrm{H}_{2} \mathrm{O}_{2}$ in PBS) to detect MyHC by immunocytochemistry. The nuclei were counter-stained with hematoxylin. Images were recorded with a microscope (Axiovert 35; Carl Zeiss MicroImaging) with either 4X NA 0.10 or 10X NA 0.25 Achrostigmat objective lenses with a digital camera (Canon, EOS D60; Japan).

\subsection{Transcription Reporter Gene Assays}

$\mathrm{C} 2 \mathrm{C} 12$ myoblasts were transfected by a standard calcium phosphate-DNA precipitation method with the indicated reporter gene and expression constructs and $\mathrm{pCMV-} \beta$-galactosidase to monitor transfection efficiency. After transfection, the cells were washed with PBS and maintained in GM and then treated as indicated. Total cellular protein was extracted with luciferase lysis buffer $(20 \mathrm{mM}$ Tris-HCl pH7.4, 0.1\% Triton X-100). Luciferase and $\beta$-galactosidase enzyme assays were performed according to the manufacturer's protocol (Promega). Luciferase activity was quantified using a 
luminometer (Berthold Luma; USA, 9501) and standardized according to $\beta$-galactosidase activity. Relative Luciferase units normalized for $\beta$-galactosidase activity (relative luciferase unit; RLU) were determined and plotted as an average of triplicate determinations and error bars represent standard deviations of the triplicate values.

Author Contributions: T.M., A.A. and J.C.M. designed the project and the individual experiments. T.M. performed experiments in Figure 2, Figure 3, and Figure 4. A.A. performed experiments in Figure 1. T.M., A.A., and J.C.M. wrote and edited the manuscript. All authors have read and agreed to the published version of the manuscript.

Funding: This research was funded by a Discovery Grant from The Natural Sciences and Engineering Research Council of Canada (NSERC) to JCM. Salary support for TM was provided by The Canadian Institutes of Health Research (CIHR).

Acknowledgments: We thank Joseph Chan (in memoriam) for technical assistance. We also thank Nezeka S. Alli for critical reading of this manuscript.

Conflicts of Interest: The authors declare no conflict of interest.

\section{Abbreviations}

TGF $\beta \quad$ Transforming growth factor beta

Smad Mothers against decapentaplegic

MEK Dual specificity mitogen-activated protein kinase kinase

ERK Extracellular signal-regulated kinase

MyoD Myoblast determination protein 1

\section{References}

1. Massague, J. TGFbeta in Cancer. Cell 2008, 134, 215-230. [CrossRef]

2. Ten Dijke, P.; Arthur, H.M. Extracellular control of TGFbeta signalling in vascular development and disease. Nat. Rev. Mol. Cell Biol. 2007, 8, 857-869. [CrossRef]

3. Schmierer, B.; Hill, C.S. TGFbeta-SMAD signal transduction: Molecular specificity and functional flexibility. Nat. Rev. Mol. Cell Biol. 2007, 8, 970-982. [CrossRef] [PubMed]

4. Rubtsov, Y.P.; Rudensky, A.Y. TGFbeta signalling in control of T-cell-mediated self-reactivity. Nat. Rev. Immunol. 2007, 7, 443-453. [CrossRef] [PubMed]

5. Wrana, J.L. Regulation of Smad activity. Cell 2000, 100, 189-192. [CrossRef]

6. Aziz, A.; Miyake, T.; Engleka, K.A.; Epstein, J.A.; McDermott, J.C. Menin expression modulates mesenchymal cell commitment to the myogenic and osteogenic lineages. Dev. Biol. 2009, 332, 116-130. [CrossRef]

7. Miyazono, K.; ten Dijke, P.; Heldin, C.H. TGF-beta signaling by Smad proteins. Adv. Immunol. 2000, 75, 115-157. [PubMed]

8. Ten Dijke, P.; Hill, C.S. New insights into TGF-beta-Smad signalling. Trends Biochem. Sci. 2004, 29, 265-273. [CrossRef] [PubMed]

9. Holmes, A.; Abraham, D.J.; Sa, S.; Shiwen, X.; Black, C.M.; Leask, A. CTGF and SMADs, maintenance of scleroderma phenotype is independent of SMAD signaling. J. Biol. Chem. 2001, 276, 10594-10601. [CrossRef]

10. Secker, G.A.; Shortt, A.J.; Sampson, E.; Schwarz, Q.P.; Schultz, G.S.; Daniels, J.T. TGFbeta stimulated re-epithelialisation is regulated by CTGF and Ras/MEK/ERK signalling. Exp. Cell Res. 2008, 314, 131-142. [CrossRef]

11. Kollias, H.D.; Perry, R.L.; Miyake, T.; Aziz, A.; McDermott, J.C. Smad7 promotes and enhances skeletal muscle differentiation. Mol. Cell Biol. 2006, 26, 6248-6260. [CrossRef] [PubMed]

12. Bengal, E.; Ransone, L.; Scharfmann, R.; Dwarki, V.J.; Tapscott, S.J.; Weintraub, H.; Verma, I.M. Functional antagonism between c-Jun and MyoD proteins: A direct physical association. Cell 1992, 68, 507-519. [CrossRef]

13. Perry, R.L.; Parker, M.H.; Rudnicki, M.A. Activated MEK1 binds the nuclear MyoD transcriptional complex to repress transactivation. Mol. Cell 2001, 8, 291-301. [CrossRef]

14. Li, L.; Chambard, J.C.; Karin, M.; Olson, E.N. Fos and Jun repress transcriptional activation by myogenin and MyoD: The amino terminus of Jun can mediate repression. Genes Dev. 1992, 6, 676-689. [CrossRef] [PubMed] 
15. Namura, S.; Iihara, K.; Takami, S.; Nagata, I.; Kikuchi, H.; Matsushita, K.; Moskowitz, M.A.; Bonventre, J.V.; Alessandrini, A. Intravenous administration of MEK inhibitor U0126 affords brain protection against forebrain ischemia and focal cerebral ischemia. Proc. Natl. Acad. Sci. USA 2001, 98, 11569-11574. [CrossRef]

16. Jinnin, M.; Ihn, H.; Tamaki, K. Characterization of SIS3, a novel specific inhibitor of Smad3, and its effect on transforming growth factor-beta1-induced extracellular matrix expression. Mol. Pharmacol. 2006, 69, 597-607. [CrossRef]

17. Qureshi, H.Y.; Ricci, G.; Zafarullah, M. Smad signaling pathway is a pivotal component of tissue inhibitor of metalloproteinases-3 regulation by transforming growth factor beta in human chondrocytes. Biochim. Biophys. Acta 2008, 1783, 1605-1612. [CrossRef]

18. Zhu, H.; Kavsak, P.; Abdollah, S.; Wrana, J.L.; Thomsen, G.H. A SMAD ubiquitin ligase targets the BMP pathway and affects embryonic pattern formation. Nature 1999, 400, 687-693. [CrossRef]

19. Dennler, S.; Itoh, S.; Vivien, D.; ten Dijke, P.; Huet, S.; Gauthier, J.M. Direct binding of Smad3 and Smad4 to critical TGF beta-inducible elements in the promoter of human plasminogen activator inhibitor-type 1 gene. EMBO J. 1998, 17, 3091-3100. [CrossRef]

20. Yue, J.; Mulder, K.M. Requirement of Ras/MAPK pathway activation by transforming growth factor beta for transforming growth factor beta 1 production in a Smad-dependent pathway. J. Biol. Chem. 2000, 275, 30765-30773. [CrossRef]

21. Watanabe, H.; de Caestecker, M.P.; Yamada, Y. Transcriptional cross-talk between Smad, ERK1/2, and p38 mitogen-activated protein kinase pathways regulates transforming growth factor-beta-induced aggrecan gene expression in chondrogenic ATDC5 cells. J. Biol. Chem. 2001, 276, 14466-14473. [CrossRef]

22. Miyake, T.; Alli, N.S.; Aziz, A.; Knudson, J.; Fernando, P.; Megeney, L.A.; McDermott, J.C. Cardiotrophin-1 maintains the undifferentiated state in skeletal myoblasts. J. Biol. Chem. 2009, 284, 19679-19693. [CrossRef] [PubMed]

23. Kollias, H.D.; McDermott, J.C. Transforming growth factor-beta and myostatin signaling in skeletal muscle. J. Appl. Physiol. 2008, 104, 579-587. [CrossRef] [PubMed]

24. Massague, J.; Cheifetz, S.; Endo, T.; Nadal-Ginard, B. Type beta transforming growth factor is an inhibitor of myogenic differentiation. Proc. Natl. Acad. Sci. USA 1986, 83, 8206-8210. [CrossRef] [PubMed]

25. Spizz, G.; Hu, J.S.; Olson, E.N. Inhibition of myogenic differentiation by fibroblast growth factor or type beta transforming growth factor does not require persistent c-myc expression. Dev. Biol. 1987, 123, 500-507. [CrossRef]

26. Sapkota, G.; Knockaert, M.; Alarcon, C.; Montalvo, E.; Brivanlou, A.H.; Massague, J. Dephosphorylation of the linker regions of Smad1 and Smad2/3 by small C-terminal domain phosphatases has distinct outcomes for bone morphogenetic protein and transforming growth factor-beta pathways. J. Biol. Chem. 2006, 281, 40412-40419. [CrossRef]

27. Liu, C.; Gaca, M.D.; Swenson, E.S.; Vellucci, V.F.; Reiss, M.; Wells, R.G. Smads 2 and 3 are differentially activated by transforming growth factor-beta (TGF-beta) in quiescent and activated hepatic stellate cells. Constitutive nuclear localization of Smads in activated cells is TGF-beta-independent. J. Biol. Chem. 2003, 278, 11721-11728. [CrossRef]

28. Massague, J. Integration of Smad and MAPK pathways: A link and a linker revisited. Genes Dev. 2003, 17, 2993-2997. [CrossRef]

29. Kretzschmar, M.; Doody, J.; Timokhina, I.; Massague, J. A mechanism of repression of TGFbeta/Smad signaling by oncogenic Ras. Genes Dev. 1999, 13, 804-816. [CrossRef]

30. De la Serna, I.L.; Ohkawa, Y.; Berkes, C.A.; Bergstrom, D.A.; Dacwag, C.S.; Tapscott, S.J.; Imbalzano, A.N. MyoD targets chromatin remodeling complexes to the myogenin locus prior to forming a stable DNA-bound complex. Mol. Cell Biol. 2005, 25, 3997-4009. [CrossRef]

31. Armand, A.S.; Bourajjaj, M.; Martinez-Martinez, S.; el Azzouzi, H.; da Costa Martins, P.A.; Hatzis, P.; Seidler, T.; Redondo, J.M.; De Windt, L.J. Cooperative synergy between NFAT and MyoD regulates myogenin expression and myogenesis. J. Biol. Chem. 2008, 283, 29004-29010. [CrossRef] [PubMed]

32. Deato, M.D.; Marr, M.T.; Sottero, T.; Inouye, C.; Hu, P.; Tjian, R. MyoD targets TAF3/TRF3 to activate myogenin transcription. Mol. Cell 2008, 32, 96-105. [CrossRef] [PubMed]

33. Miyake, T.; Alli, N.S.; McDermott, J.C. Nuclear function of Smad7 promotes myogenesis. Mol. Cell Biol. 2010, 30, 722-735. [CrossRef] 
34. Hayashida, T.; Decaestecker, M.; Schnaper, H.W. Cross-talk between ERK MAP kinase and Smad signaling pathways enhances TGF-beta-dependent responses in human mesangial cells. FASEB J. 2003, 17, 1576-1578. [CrossRef]

35. McMahon, J.A.; Takada, S.; Zimmerman, L.B.; Fan, C.M.; Harland, R.M.; McMahon, A.P. Noggin-mediated antagonism of BMP signaling is required for growth and patterning of the neural tube and somite. Genes Dev. 1998, 12, 1438-1452. [CrossRef] [PubMed]

36. Moon, B.S.; Yoon, J.Y.; Kim, M.Y.; Lee, S.H.; Choi, T.; Choi, K.Y. Bone morphogenetic protein 4 stimulates neuronal differentiation of neuronal stem cells through the ERK pathway. Exp. Mol. Med. 2009, 41, 116-125. [CrossRef]

37. Tripathi, S.; Miyake, T.; McDermott, J.C. Smad7:beta-catenin complex regulates myogenic gene transcription. Cell Death Dis. 2019, 10, 387. [CrossRef]

38. Levy, L.; Hill, C.S. Smad4 dependency defines two classes of transforming growth factor \{beta\} (TGF-\{beta\}) target genes and distinguishes TGF-\{beta\}-induced epithelial-mesenchymal transition from its antiproliferative and migratory responses. Mol. Cell Biol. 2005, 25, 8108-8125. [CrossRef]

39. Rousse, S.; Lallemand, F.; Montarras, D.; Pinset, C.; Mazars, A.; Prunier, C.; Atfi, A.; Dubois, C. Transforming growth factor-beta inhibition of insulin-like growth factor-binding protein-5 synthesis in skeletal muscle cells involves a c-Jun N-terminal kinase-dependent pathway. J. Biol. Chem. 2001, 276, 46961-46967. [CrossRef]

40. Goldstein, J.A.; Kelly, S.M.; LoPresti, P.P.; Heydemann, A.; Earley, J.U.; Ferguson, E.L.; Wolf, M.J.; McNally, E.M. SMAD signaling drives heart and muscle dysfunction in a Drosophila model of muscular dystrophy. Hum. Mol. Genet. 2011, 20, 894-904. [CrossRef]

41. Guttridge, D.C. A TGF-beta pathway associated with cancer cachexia. Nat. Med. 2015, 21, 1248-1249. [CrossRef] [PubMed]

42. Long, K.K.; Montano, M.; Pavlath, G.K. Sca-1 is negatively regulated by TGF-beta1 in myogenic cells. FASEB J. 2011, 25, 1156-1165. [CrossRef] [PubMed]

43. Cencetti, F.; Bernacchioni, C.; Nincheri, P.; Donati, C.; Bruni, P. Transforming growth factor-beta1 induces transdifferentiation of myoblasts into myofibroblasts via up-regulation of sphingosine kinase-1/S1P3 axis. Mol. Biol. Cell 2010, 21, 1111-1124. [CrossRef] [PubMed]

44. Mansour, S.J.; Resing, K.A.; Candi, J.M.; Hermann, A.S.; Gloor, J.W.; Herskind, K.R.; Wartmann, M.; Davis, R.J.; Ahn, N.G. Mitogen-activated protein (MAP) kinase phosphorylation of MAP kinase kinase: Determination of phosphorylation sites by mass spectrometry and site-directed mutagenesis. J. Biochem. 1994, 116, 304-314. [CrossRef] [PubMed]

(C) 2020 by the authors. Licensee MDPI, Basel, Switzerland. This article is an open access article distributed under the terms and conditions of the Creative Commons Attribution (CC BY) license (http://creativecommons.org/licenses/by/4.0/). 